\title{
Rancang Bangun Prototype Pengering Gabah Otomatis Dengan Pengendali Sensor Kelembaban Dan Suhu Berdasarkan Suhu Ruang Berbasis Mikrokontroler ATmega 328
}

\author{
Mohammad Al Faris ${ }^{1}$, Sri Purwiyanti ${ }^{2}$, Herlinawati $^{3}$ \\ Jurusan Teknik Elektro Universitas Lampung, Bandar Lampung \\ J1. Prof. Sumantri Brojonegoro No.1 Bandar Lampung 35145 \\ ${ }^{1}$ malfaris10@gmail.com \\ ${ }^{2}$ sri.purwiyanti@eng.unila.ac.id \\ ${ }^{3}$ herlinawati@eng.unila.ac.id
}

Intisari - Pada zaman modern banyak produk-produk manufaktur yang serba otomatis untuk membantu manusia dalam mengerjakan pekerjaannya. Salah satu kerja yang membutuhkan bantuan mesin adalah pengering gabah. Pada saat ini pengeringan gabah dilakukan dengan konvensional yaitu dijemur di terik matahari dan bila cuaca mendung maka tidak dilakukan penjemuran. Oleh karena itu dibutuhkan alat yang terintegrasi. Alat pengeringan otomatis ini menggunakan mikrokontroler untuk mengatur kerja blower DC, motor driver L298N, Motor DC pengaduk gabah, Sensor suhu, dan Sensor kelembaban \& suhu. Pada alat ini menggunakan gabah dengan massa $0.5 \mathrm{~kg}, 1 \mathrm{~kg}, 1.5 \mathrm{~kg}, 2 \mathrm{~kg}$ dan $3 \mathrm{~kg}$ waktu pengeringan gabah dengan rata-rata waktu di setiap massa $36,52.6,65.8,73.2$, dan 83.2 menit dengan kelembaban dan suhu awal sama yaitu $80 \%$ \& $26^{\circ} \mathrm{C}$ dan daya 120 Watt. Hasil dalam Proses selanjutnya yaitu dengan kelembaban awal $40 \%$, $50 \%$ dan $60 \%$ dengan rata-rata waktu berturut-turut yaitu $34.8,47.8$, dan 63.2 menit. Dan hasil dari proses pengujian terakhir yang dilakukan di pagi hari dengan kelembaban dan suhu awal $89 \%$ \& $20^{\circ} \mathrm{C}$, siang hari dengan kelembaban dan suhu awal $80 \%$ dan $26^{\circ} \mathrm{C}$ dan sore hari dengan kelembaban dan suhu awal $85 \%$ dan $23^{\circ} \mathrm{C}$ didapatkan rata-rata waktu berturu-turut yaitu 75, 52.6 dan 63.4 Menit. Kelembaban standar yang telah diatur adalah $32 \%$ kelembaban tersebut hampir setara dengan kelembaban gabah yang telah disurvey yaitu $25 \%$ di tengah terik matahari dengan suhu $35^{\circ} \mathrm{C}$.

Kata kunci - Mikrokontroler, Pengeringan Gabah, Motor DC.

Abstract - In modern times many manufacturing products are completely automated to help people in their work. One job that requires the help of a machine is grain dryer. At this time grain drying is done conventionally, which is dried in the sun and when the weather is cloudy, drying is not done. Therefore we need an integrated tool. This automatic drying tool uses a microcontroller to regulate the work of DC blowers, L298N motor drivers, grain stirring DC motors, temperature sensors, and humidity \& temperature sensors. In this tool using grain with a mass of $0.5 \mathrm{~kg}, 1 \mathrm{~kg}, 1.5 \mathrm{~kg}, 2 \mathrm{~kg}$ and $3 \mathrm{~kg}$ of grain drying time with an average time in each mass $36,52.6,65.8$, 73.2, and 83.2 minutes with the same humidity and initial temperature ie $80 \%$ \& $26^{\circ} \mathrm{C}$ and 120 Watt power. The results in the next process are with initial humidity of $40 \%, 50 \%$ and $60 \%$ with an average of consecutive times of 34.8, 47.8, and 63.2 minutes. And the results of the last testing process conducted in the morning with humidity and initial temperature of $89 \%$ \& $20^{\circ} \mathrm{C}$, during the day with humidity and initial temperature of $80 \%$ and $26^{\circ} \mathrm{C}$ and in the afternoon with humidity and initial temperature of $85 \%$ and $23^{\circ} \mathrm{C}$ obtained an average time respectively 75, 52.6 and 63.4 Minutes. The standard humidity that has been set is 32\%, the humidity is almost equivalent to the humidity of the grain that has been surveyed, which is $25 \%$ in the hot sun with a temperature of $35^{\circ} \mathrm{C}$.

Keywords - Microcontroller, Grain Drying, DC Motor. 


\section{PENDAHULUAN}

Indonesia merupakan negara agraris yang memiliki sumber daya alam yang beraneka ragam dan memiliki wilayah yang cukup luas. Mungkin hal inilah yang membuat Indonesia menjadi salah satu negara agraris terbesar di dunia. Namun ironisnya Indonesia masih mengimpor beras dari negara lain, padahal sudah jelas sekali bahwa Indonesia mampu menghasilkan beras lokal sendiri yang tak kalah berkualitas dengan beras impor dari negara lain. Salah satu alasan dilakukannya impor beras adalah tak lain karena gabah yang dihasilkan para petani Indonesia kurang maksimal jumlahnya untuk dijadikan cadangan beras nasional. Hal ini disebabkan karena proses pengeringan gabah yang membutuhkan waktu yang lama sehingga gabah yang dihasilkan belum memenuhi kebutuhan beras di Indonesia. Banyak kendala yang dirasakan oleh para petani untuk menghasilkan padi berkualitas yang sesuai standar BULOG. Penyebab kurang maksimalnya kualitas padi tersebut adalah karena cuaca yang sulit diprediksi, lahan sempit yang menyebabkan sulitnya proses pengeringan padi sehingga membutuhkan waktu yang lama untuk menghasilkan padi dengan kualitas baik. Dalam jurnal yang berjudul Rancang Bangun Sistem Pengering Gabah Dengan Menggunakan Arduino, hanya menggunakan sensor kapasitif untuk mengetahui kadar air dan dalam pengeringan hanya dibantu oleh blower hasilnya padi masih lembab dan kurang optimal dalam pengeringannya [1].

Selain masalah diatas terdapat masalah lain yang dapat mempengaruhi kualitas beras nantinya antara lain tumbuhnya jamur, bakteri, hama dan kualitas padi yang kurang baik akibat lembabnya padi yang disimpan di dalam gudang karena proses pengeringan padi yang kurang sempurna. Dalam jurnal yang berjudul Rancang Bangun Pengering Padi Otomatis Berbasis Mikrokontroler AT89852, di rancang bangun yang hanya berparameter pada suhu dan kelembaban padi nantinya akan ditampilkan pada LCD. Hasil dari rancang bangun ini hanya sebatas pengecekan kelembaban padi yang berada pada gudang hal tersebut terjadi karena terhambatnya pengeringan pasca panen dikarenakan cuaca yang kurang mendukung. Petani sangat memanfaatkan tingkat kecerahan matahari untuk menjemur padi dalam proses pengeringan dan dilakukan kurang lebih selama satu minggu untuk mendapatkan hasil pengeringan yang sesuai standar dan berkualitas baik [2].

\section{KAJIAN PUSTAKA}

\section{A. Arduino ATmega 328}

Arduino merupakan rangkaian elektronik yang bersifat open source, serta memiliki perangkat keras dan lunak yang mudah untuk digunakan. Arduino dapat mengenali lingkungan sekitarnya melalui berbagai jenis sensor dan dapat mengendalikan lampu, motor, dan berbagai jenis aktuator lainnya. Arduino mempunyai banyak jenis, di antaranya Arduino Uno, Arduino Mega 2560, Arduino Fio dan lainnya [3].

\section{B. Arduino IDE}

Arduino Development Environment terdiri dari editor teks untuk menulis kode, sebuah area pesan, sebuah konsul, sebuah toolbar dengan tomboltombol untuk fungsi yang umum dan beberapa menu. Arduino Development Environment terhubung ke arduino board untuk meng-upload program dan juga untuk berkomunikasi dengan arduino board [3].

\section{Motor DC}

Motor DC atau motor listrik adalah perangkat elektromagnetis yang mengubah energi listrik menjadi energi mekanik. Energi mekanik ini digunakan untuk melakukan suatu kerja yang bersifat mekanis. Motor DC memerlukan suplai tegangan yang searah pada kumparan medan untuk diubah menjadi energi mekanik [4].

\section{Motor Driver}

L298N adalah contoh IC yang dapat digunakan sebagai driver motor dc. IC ini menggunakan prinsip kerja $H$-Bridge. Tiap H-Bridge dikontrol menggunakan level tegangan TTL yang berasal dari output mikrokontroler. L298N dapat mengontrol 2 buah motor dc. 
Tegangan yang dapat digunakan untuk mengendalikan robot bisa mencapai tegangan $46 \mathrm{Vdc}$ dan arus mencapai 2 A untuk setiap kanalnya [4].

\section{E. Sensor Kelembaban dan Suhu}

Sensor kelembaban dan suhu merupakan sensor elektronika yang bekerja berdasarkan konsep kapasitif. Sensor ini bekerja berdasarkan perubahan muatan energi listrik yang dapat disimpan oleh sensor akibat perubahan jarak lempeng, perubahan luas penampang dan perubahan volume dielektrikum sensor kapasitif tersebut. Konsep kapasitor yang digunakan dalam sensor kapasitif adalah proses menyimpan dan melepas energi listrik dalam bentuk muatan-muatan listrik pada kapasitor yang dipengaruhi oleh luas permukaan, jarak dan bahan dielektrikum [5].

\section{METODE PENELITIAN}

Metode yang digunakan untuk mencapai tujuan penelitian ini adalah dengan merancang bangun suatu sistem. Perancangan dilakukan dengan metode Arduino IDE dengan menyatukan segala sistem yang akan dikontrol dengan Sensor suhu dan Kelembaban dan sistem geraknya akan dibantu dengan motor dc 20 vdc.

Pada Gambar 1 di bawah dapat dijelaskan bahwa power supply berguna untuk memenuhi kebutuhan daya dari seluruh blok rangkaian. Ketika power supply menyala maka sensor suhu dan kelembaban akan mendeteksi jumlah kelembaban dan suhu yang terdapat pada padi. Setelah suhu dan kelembaban sudah diketahui sensor tersebut akan memberi perintah pada arduino untuk menggerakkan motor. Pada rancangan alat ini juga menggunakan motor driver L298N sebagai modul pengendali kecepatan dan arah motor DC.

Sensor kelembaban dan suhu akan aktif otomatis yang akan memerintahkan arduino dalam penghidupan relay dan blower yang nantinya akan meniupkan angin panas dari blower dan heater lalu selanjutnya bila padi sudah kering maka akan terdapat notifikasi berupa tampilan dari led hijau dan merah, ketika padi belum kering maka led akan menunjukkan di warna hijau dan ketika sudah mencapai standar kering dari pada padi maka led akan berubah menjadi merah. Untuk lebih jelasnya mengenai prinsip kerja dari perangkat sistem yang dibuat.

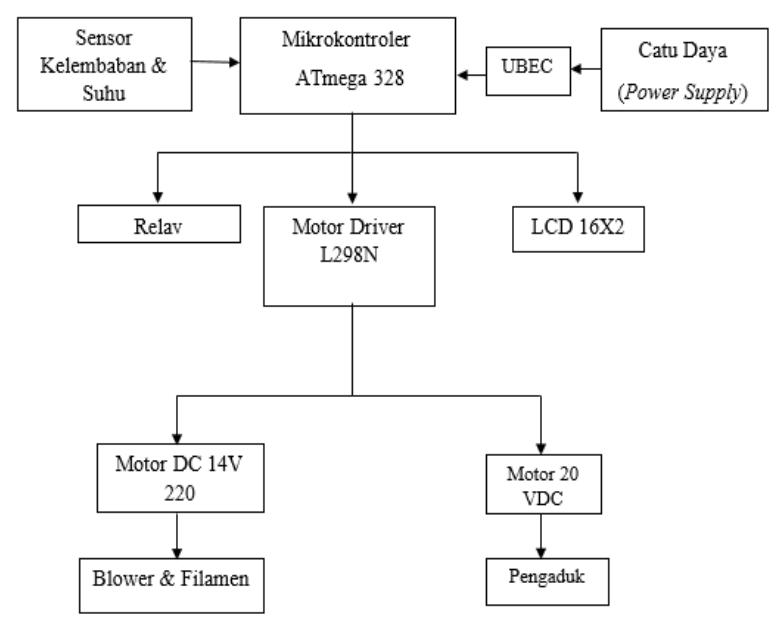

Gbr.1 Diagram Block Sistem

Mengenai prinsip kerja dari keseluruhan sistem sudah diuraikan melalui flowchart dibawah ini

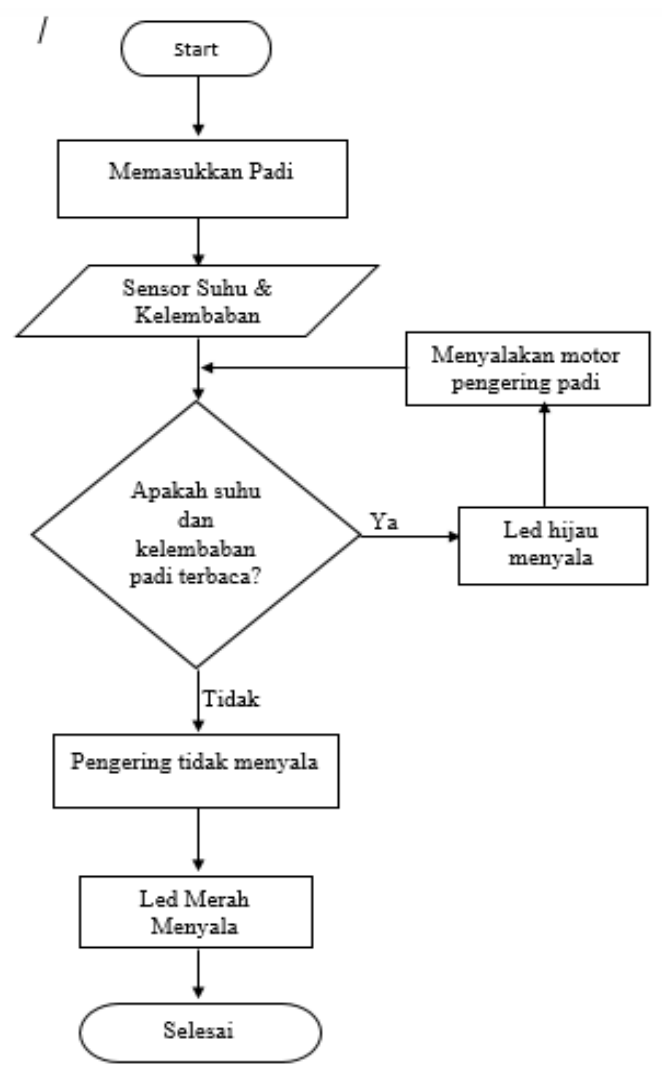

Gbr.2 Flowchart Sistem

Saat padi sudah dimasukkan maka sensor suhu dan kelembaban akan membaca suhu dan kelembaban padi. Saat suhu rendah dan kelembaban tinggi yang terbaca maka led hijau menyala dan menyalakan motor pengering padi pada gear yang akan memutar 
pengaduk dalam tabung yang akan mengaduk padi jika tidak terbaca atau suhu padi tinggi dan kelembaban rendah maka pengering padi dan motor tidak bergerak dan led merah menyala maka proses selesai.

\section{HASIL PENELITIAN DAN PEMBAHASAN}

Data diperoleh dari hasil pengujian alat dan pengambilan data mulai dari pengujian kapasitas, pengujian berdasarkan efek kelembaban awal terhadap waktu dan pengujian berdasarkan suhu awal ruangan dan kondisi alam. Hasil masing-masing data dalam tabel diperoleh dari rata-rata keseluruhuan setiap percobaan. Tabel 1 adalah tabel rata-rata waktu dari keseluruhan pengujian alat.

Tabel 1. Rata-rata waktu dalam pengujian kapasitas

\begin{tabular}{|c|c|c|}
\hline No. & Massa & $\begin{array}{c}\text { Waktu Rata- } \\
\text { Rata }\end{array}$ \\
\hline 1. & $0.5 \mathrm{Kg}$ & 36 Menit \\
\hline 2. & $1 \mathrm{Kg}$ & 52.6 Menit \\
\hline 3 & $1.5 \mathrm{Kg}$ & 65.8 Menit \\
\hline 4. & $2 \mathrm{Kg}$ & 73.2 Menit \\
\hline 5. & $3 \mathrm{Kg}$ & 83.2 Menit \\
\hline
\end{tabular}

Berdasarkan data di atas dapat disimpulkan bahwa waktu rata-rata saat percobaan pertama yaitu massa $0.5 \mathrm{Kg}$ adalah selama 36 Menit menuju standar kelembaban yang telah ditentukan yaitu $32 \%$. Kemudian percobaan kedua yaitu massa 1 Kg menghasilkan waktu selama 52.6 Menit menuju standar kelembaban yang telah ditentukan yaitu $32 \%$. Lalu percobaan ketiga yaitu massa $1.5 \mathrm{Kg}$ menghasilkan waktu selama 65.8 menit menuju standar kelembaban yang telah ditentukan yaitu $32 \%$. Kemudian percobaan keempat dengan massa $2 \mathrm{Kg}$ menghasilkan waktu rata-rata selama 73.2 Menit dan percobaan terakhir dengan mass $3 \mathrm{Kg}$ menghasilkan waktu rata-rata 83.2 Menit menuju kelembaban yang telah ditentukan yaitu $32 \%$.
Tebel 2. Rata-rata waktu efek kelembaban awal

\begin{tabular}{|c|c|c|}
\hline No. & Kelembaban Awal & $\begin{array}{c}\text { Waktu Rata- } \\
\text { Rata }\end{array}$ \\
\hline 1. & $40 \%$ & 34.8 Menit \\
\hline 2. & $50 \%$ & 47.8 Menit \\
\hline 3. & $60 \%$ & 63.2 Menit \\
\hline
\end{tabular}

Berdasarkan data diatas dapat disimpulkan bahwa waktu rata-rata saat percobaan dengan standar kapasitas $1 \mathrm{Kg}$ pertama yaitu Kelembaban awal $40 \%$ adalah selama 34.8 menit menuju standar kelembaban yang telah ditentukan yaitu $32 \%$. Kemudian percobaan kedua dengan kelembaban awal 50\% menghasilkan waktu selama 47.8 menit menuju standar kelembaban yang telah ditentukan yaitu $32 \%$. Lalu percobaan terakhir yaitu dengan kelembaban awal $60 \%$ menghasilkan waktu selama 63.2 menit menuju standar kelembaban yang telah ditentukan yaitu $32 \%$.

Tabel 3 Rata-rata waktu suhu awal ruang berdasarkan kondisi lingkungan

\begin{tabular}{|c|c|c|}
\hline NO. & $\begin{array}{c}\text { Waktu Saat } \\
\text { Pengujian }\end{array}$ & $\begin{array}{c}\text { Waktu Rata- } \\
\text { Rata }\end{array}$ \\
\hline 1. & Pagi Hari & 75 Menit \\
\hline 2. & Siang Hari & 52.6 Menit \\
\hline 3. & Sore Hari & 63.4 Menit \\
\hline
\end{tabular}

Berdasarkan data diatas dapat disimpulkan bahwa waktu rata-rata saat percobaan dengan standar kapasitas $1 \mathrm{Kg}$ pertama yaitu suhu dan kelembaban awal tabung tanpa gabah saat pagi hari $20^{\circ} \mathrm{C}, 89 \%$ adalah selama 75 menit menuju standar kelembaban yang telah ditentukan yaitu 32\%. Kemudian percobaan kedua dengan suhu dan kelembaban awal tabung tanpa gabah saat siang hari $26^{\circ} \mathrm{C}, 80 \%$ menghasilkan waktu selama 52.6 menit menuju standar kelembaban yang telah ditentukan yaitu $32 \%$. Lalu percobaan terakhir yaitu dengan suhu dan kelembaban awal tabung tanpa gabah saat sore hari $23^{\circ} \mathrm{C}$, $85 \%$ menghasilkan waktu selama 63.4 menit menuju standar kelembaban yang telah ditentukan yaitu $32 \%$. 


\section{KESIMPULAN DAN SARAN}

\section{A. Kesimpulan}

Adapun kesimpulan yang diperoleh dari penelitian ini adalah sebagai berikut :

1. Telah terealisasi alat pengering bulir gabah otomatis menggunakan sensor suhu, blower, motor driver, dan motor DC berbasis mikrokontroler Arduino ATmega328.

2. Pada perancangan alat pengering gabah otomatis ini telah terbukti sensor suhu Ds18b20 dan sensor suhu kelembaban DHT11 berfungsi baik dan mampu menjadi umpan balik motor pengaduk dan motor blower. Mikrokontroler Arduino telah berhasil mengendalikan waktu capai pada motor pengaduk, motor blower serta waktu keseluruhan sistem alat.

3. Pada pengujian pemutaran pengaduk motor dc terbukti dapat mengaduk gabah dengan beragam massa dan dapat diatur sesuai kebutuhan dan kapasitas dalam tabung pengadukan.

4. Pada proses pengeringan gabah rata-rata waktu pengeringan pada siang hari yang biasanya digunakan untuk mengeringkan gabah secara konvensional mencapai 52.6 Menit dengan berat $1 \mathrm{Kg}$ yang mana pengadukan gabah dibantu dengan motor pengaduk, kipas, dan tabung yang berbahan alumunium terbukti lebih efektif dibandingkan dengan terhampar tanpa bantuan sistem yang lain.

5. Pengambilan data tersebut telah dilakukan berdasarkan pada survey yang penulis lakukan dengan bertanya pada petani dan ahli dalam bidang pertanian langsung dimana kelembaban rata-rata pada gabah baru panen setelah dilakukan penjemuran gabah di tanah lapang. Penjemuran gabah pada saat terik matahari mencapai $35^{\circ} \mathrm{C}$ kelembaban gabah yang telah kering mencapai $25 \%$ bila kelembaban masih tinggi gabah akan dijemur kembali hingga kelembaban mencapai titik kering.

\section{B. Saran}

Adapun kesimpulan yang diperoleh dari penelitian ini adalah sebagai berikut :

1. Pada penelitian selanjutnya diharapkan agar memperhatikan desain dari keseluruhan sistem alat dari mekanikal dan elektrikal yang lebih efektif.
2. Pada pembuatan alat pengering bulir gabah otomatis banyak menggunakan Alumunium maka alat ini harus dilakukan uji kehigenisan dan sterilisasi tiap part komponen agar dapat digunakan masal.

3. Pada penelitian selanjutnya, penggunaan mata pengaduk bulir gabah harus di desain secara otomatis dan berbentuk spiral untuk mengubah tingkat kemerataan sehingga menjadi lebih efisien dalam mengatur ratanya gabah dalam tabung.

\section{DAFTAR PUSTAKA}

[1] Hanan, Muhammad. 2012. Rancang Bangun Sistem Pengering Gabah Dengan Menggunakan Arduino.

[2] Teguh Hidayat. 2016. Semua Bisa Menjadi Programmer Visual basic 2010. PT Elex Media Komputindo. Jakarta.

[3] Djuandi. 2016. Pemrograman Arduino. PT Rinjani Books. Surabaya.

[4] Effendi. Zuhal. 2017. Motor DC Pemrograman Dalam Arduino. PT Exess Motor. Jakarta.

[5] Digital Meter Indonesia. 2016. Jenisjenis sensor kelembaban. Komponen Elektonika. PT. Widisarana Indonesia. Bandung. 